\title{
Supporting Positive Behaviour Change for At-Risk Students: A Best Practice Checklist for Schools
}

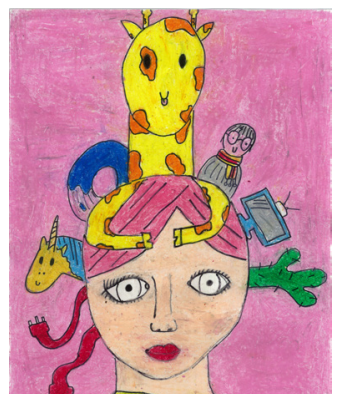

\begin{abstract}
The current study aims to review the literature regarding Tier Two behavioural interventions for children aged 5 to 13, and identify the core components which the research suggests are important to their effectiveness and/or social validity. Trends within the research indicate schools are more likely to adapt interventions to fit their own school context or meet what is socially valid to their teachers, students, and community, as opposed to implementing an intervention with excellent (empirically-based) fidelity. Through compiling the best-practice components of Tier Two interventions, a checklist has been created for schools to use when they are making adaptation to interventions, or developing their own. This supports the approach schools are already taking, promotes flexibility, and allows schools the space to develop cultural and social relevancy in Tier Two interventions; while still incorporating the components of what the wider literature advocates is effective with at-risk students.
\end{abstract}

\section{Research paper}

\section{Keywords:}

at-risk students, behaviour interventions, positive behaviour intervention and support

\section{BACKGROUND}

\section{School-Wide Positive Behaviour for Learning}

Positive Behaviour Intervention and Support (PBIS) is a model of promoting positive school behaviour and was developed by Horner, Sugai and others at the University of Oregon in the 1990's (Hoyle, Marshall \& Yell, 2011; Ministry of Education, 2016). PBIS is based on the concept that positive behaviour can be taught and the school environment adapted to promote this. There is sufficient research to suggest that PBIS is an evidence-based approach to preventing and addressing problem behaviours at school (MOE, 2015; Lewis \& Sugai, 1999; Sugai \& Horner, 2002). Positive Behaviour for Learning - School Wide (PB4LSW), based on PBIS, has been adapted for the New
Zealand context and has been implemented with the support of Ministry of Education specialists in 600 New Zealand schools (MOE, 2016). The goal of PB4L-SW is to provide a positive school environment which fosters pro-social behaviour and academic skills, and decreases problem behaviours (MOE, 2015). To achieve this, the school environment provides clear expectations for behaviour, which are taught explicitly, and children receive consistent feedback for appropriate and inappropriate behaviour (Sugai \& Horner, 2002; Sugai, Horner \& Gresham, 2002).

\section{Response to Intervention}

PB4L-SW uses a Response to Intervention (RTI) model to guide systematic, proactive, and evidence-based decision making in terms identifying and supporting students based on their needs (Hoyle et al., 2011; Sugai, Horner \& Gresham, 2002). RTI consists of three levels of intervention which increase in intensity and provide a continuum of behaviour support (Hoyle et al., 2011). This model ensures that students who do require support are identified quickly, and the leastintrusive strategies are employed to promote positive behaviour (Lane, Kalberg \& Menzies, 2009). The first tier of intervention used in PB4L- SW is preventing problematic behaviours through developing, and teaching, rules and routines which reflect school-wide expectations for positive behaviour (Sugai \& Horner, 2006). Approximately 15 percent of students will not respond to primary intervention and will require more targeted support (Sugai \& Horner, 2006). These students are identified by collecting school-wide behaviour data (usually the rate of minor and major incidents recorded by teachers), and are considered 'at-risk' for developing severe behaviour problems (Sugai \& Horner, 2006). Tier Two interventions intend to prevent serious behaviour problems. They are usually delivered in small groups to targeted children, and involve the teaching of specific academic, social, or behavioural skills (Lane, Kalberg \& Menzies, 2009; Cook \& Tankersley, 2012). Sugai and Horner (2006) estimate that approximately 5 percent of students will not respond to secondary intervention and will demonstrate severe and challenging behaviours. This 
group of students will then become eligible for tertiary intervention which involves the implementation of individualised, wrap-around evidence-based intervention (Sugai \& Horner, 2006). The RTI model supports the Ministry of Education's focus on inclusive practice in New Zealand as it guides the delivery of appropriate support, accurate identification, and reduces exclusions through teaching and reinforcing positive behaviour (Sugai and Horner, 2002; Hill \& Brown, 2013).

\section{Gaps in Knowledge}

There is considerably less research on Tier Two interventions in comparison to Tier One or Three interventions which have received extensive evaluation (Hawken, MacLeod \& Rawlings, 2007). Reviewing the literature reveals schools are largely using strategies without an evidence-base at the Tier Two level; and that those who are using empiricallysupported interventions are implementing these without fidelity (Hoyle et al., 2011). Other common findings were a lack of standardised processes for selecting evidence-based interventions, and the rarity of routine data collection to monitor student's progress is uncommon (Debnam, Pas \& Bradshaw, 2012; Hawken et al., 2007; McIntosh et al., 2009). Without robust Tier Two interventions, schools run the risk of providing ineffective support leading to ongoing behavioural issues, or wrongfully identifying eligibility for Tier Three intervention. It is concluded that schools have a need for accessible research on what works, support around how to identify the best-fit intervention, and the development of tools to assess their implementation. The current study seeks to support schools in this area by providing a summary of the research base and a practical checklist to guide development and implementation of Tier Two level interventions (see Table 1 below).

\section{BEST PRACTICE COMPONENTS OF TIER TWO INTERVENTIONS CHECKLIST}

This review of literature on Tier Two interventions reveals several components contributing to successful outcomes. Through compiling these components, a checklist has been created to guide schools in developing, adapting and evaluating their Tier Two interventions. The checklist supports schools to access the research base in a user-friendly way and guides the integration of strategies and processes grounded in empirical evidence into their practice. Another benefit of this tool is that it is non-prescriptive and promotes flexibility. Schools are able to capitalise on their knowledge of what is socially and culturally relevant within their school and wider community, and are encouraged to adapt interventions to be meaningful within their context.
Table 1

Checklist of Best Practice Components of Tier Intervention

\begin{tabular}{|l|l|}
\hline \multicolumn{2}{|l|}{ Checklist of best practice components of Tier Two interventions } \\
\hline $\begin{array}{l}\text { Clear process developed for systematic and data- } \\
\text { driven identification of students in need of Tier Two } \\
\text { intervention. }\end{array}$ & \\
\hline $\begin{array}{l}\text { Intervention builds upon well-established school-wide } \\
\text { expectations for behaviour (Tier One). }\end{array}$ & \\
\hline $\begin{array}{l}\text { Intervention is able to be implemented with small } \\
\text { groups to reduce cost and use of teachers' time. }\end{array}$ & \\
\hline $\begin{array}{l}\text { Intervention is able to provide support to students } \\
\text { quickly after identification - readily available, and } \\
\text { without any need for further assessment. }\end{array}$ & \\
\hline $\begin{array}{l}\text { Functional behavioural assessment is used to guide } \\
\text { selection or development of the intervention. }\end{array}$ & \\
\hline $\begin{array}{l}\text { Intervention includes a (low-burden) component of } \\
\text { family involvement/communication. }\end{array}$ & \\
\hline $\begin{array}{l}\text { Intervention builds/develops positive relationships } \\
\text { between students and school staff. }\end{array}$ & \\
\hline $\begin{array}{l}\text { Intervention provides regular opportunities for students } \\
\text { to receive positive feedback regarding their behaviour. }\end{array}$ & \\
\hline $\begin{array}{l}\text { Adequate training for school personnel involved in the } \\
\text { delivery of the intervention to increase buy-in from staff } \\
\text { and improve implementation fidelity. }\end{array}$ & \\
\hline $\begin{array}{l}\text { School able to provide different types, or adaptations, of } \\
\text { the interventions in order to meet the varying needs of } \\
\text { students - based on functional behavioural assessments. }\end{array}$ & \\
\hline $\begin{array}{l}\text { Where skill acquisition is contributing to behaviour } \\
\text { problems, the intervention teaches the skills required to } \\
\text { perform desired behaviour. }\end{array}$ & \\
\hline $\begin{array}{l}\text { Systematic process in place for on-going data collection } \\
\text { of students' progress. Data to be reviewed regularly } \\
\text { (every } 2 \text { weeks suggested), and used to inform decision- } \\
\text { making around intervention maintenance, fading, } \\
\text { adaptations, or increasing intensity. }\end{array}$ & \\
\hline
\end{tabular}

\section{REVIEW OF TIER TWO INTERVENTIONS}

In order to develop the best-practice checklist (Table 1), a review of the literature focusing on evidence-based interventions targeting at-risk students was undertaken. The publications were analysed for components of the interventions which were reportedly instrumental in promoting positive behaviour among at-risk students. The literature revealed that the most common and most widely-researched interventions are: The Behaviour Education Plan, Check and Connect, and various social skills training programmes including anger and anxiety management. Below is a summary of this research. Unfortunately, very little research from the New Zealand context was available to be included within this review. 


\section{The Behaviour Education Plan}

The Behaviour Education Plan (BEP) is a check-in/ check-out (CICO) system developed specifically for students requiring targeted behaviour support (Taylor-Greene, 1997, cited in March \& Horner, 2002) The programme is "designed to clarify expectations, increase the student's daily structure, increase contingent social praise from teachers/ staff members, and promote communication among the school, family, and student" (March \& Horner, 2002, p. 160). The intervention involves each of the target students (identified through a certain number of office referrals or teacher nomination) engaging in the following process: each morning the student "checks-in," for which they are reinforced with social recognition, provided with a daily BEP card which breaks the day down into classes (or however it is feasible to break the day down into shorter periods). The child gives the card to the teacher at the start of each period, and at the end the teacher provides written feedback on whether the student has met, partly met, or did not meet each of the school-wide behaviour expectations during that time. At the end of the day, the child "checks-out" by handing in the card - they again receive social validation and possibly a small tangible reward if they have got the card completed. The card is then sent home to get a parental signature and then brought back and data recorded (March \& Horner, 2002). A review was conducted consisting of 28 group and single-subject CICO studies. It was discovered that in 82 percent of the studies students demonstrated positive changes to behaviour following participation (Hawken, Bundock, Kladis, O'Keeffe \& Barrett, 2014). Several other publications reviewed in the current study found BEP to be effective in reducing problem behaviours in the significant majority of students referred (Filter et al., 2007; Hawken et al., 2007; Hawken \& Horner, 2003; McCurdy, Kunsch \& Reibstein, 2007; March \& Horner, 2002). Furthermore, it was found that BEP has been implemented with high fidelity by school personnel following training, and has scored highly on social validity rating scales among the teachers who administer it (Filter et al., 2007; Hawken et al., 2007; McCurdy et al., 2007). There is a consensus among the authors that BEP is an efficient use of resources; it is able to be implemented to a group of students at the same time, it uses up limited amounts of teachers' time, is successful for the majority of students referred, and it is able to implemented quickly after identification of the need for Tier Two intervention.

A number of additional studies have also found that the function of the students behaviour can moderate responses to the intervention and should therefore be considered during design and implementation (Lane, Capizzi, Fisher \& Ennis, 2012; March \& Horner, 2002; Todd, Campbell, Meyer \& Horner, 2008). McIntosh et al. (2009) used FACTS (Functional Assessment Checklist for Teachers and Staff) to determine the function of the behaviour for each of the 36 target children in their study. It was discovered that there were significant differences in students' responses to the intervention based on the function of the child's behaviour. CICO was found to produce statistically and clinically significant outcomes for children engaging in problem behaviours in order to gain attention, however no significant effects were found for the escape-maintained behaviours (behaviour which functions to avoid certain tasks or interactions). Additional studies have also supported this argument in their findings. March and Horner (2002) found that CICO was effective for 69 percent of students whose behaviour was attention-driven, and only effective for 27 percent of children whose behaviour was escape-maintained. Similarly, Campbell and Anderson (2008) first implemented $\mathrm{CICO}$ with two normally-developing intermediate boys and found the intervention had little to no impact. It was then modified based on an analysis of the function of the behaviour and significant results were then observed. The theme continues in both Lane et al.'s (2012) study, and Todd et al.'s (2008) research. Both studies found that the intervention produced a higher rate of positive outcomes when paired with children whose behaviour was maintained by gaining adult attention, as determined by a Functional Behaviour Assessment (FBA). These findings make sense given that $\mathrm{CICO}$ provides students with a high rate of adult attention for appropriate behaviours. It is argued that without an FBA, the student may not respond to the intervention and then it is unknown whether they require a different Tier Two intervention, or to progress to Tier 3 , potentially leading to inaccurate referral to special needs services.

\section{Check, Connect and Expect}

Check, Connect and Expect (CCE) is based on the CICO system and is recognised in the What Works Clearinghouse report as an effective evidence-based method for reducing problem behaviour (Cheney et al., 2009). Similar to the BEP described above, the intervention consists of checking in and out each day, gaining feedback regularly from teachers throughout the day, and taking home the daily report card for parents to sign. The point of difference in this intervention is the person with whom the student checks in and out with is a mentor. The relationship formed between at-risk students and the mentor is an important component of the intervention (Cheney, 
Flower \& Templeton, 2008). The student and the mentor go over the student's goals (in line with school-wide expectations) at the beginning of the day, and then during check-out they develop goals for the next day based on the feedback. Another difference is that on the report card teachers rate the students behaviour on a scale (as well as providing a positive behaviour-specific comment) which is reflected in a point system. In CCE, students are considered successful each day if they obtain 75 percent of available points. The mentor is responsible for administering positive reinforcement and recognition daily, as well as negotiating and distributing tangible rewards for agreed behavioural goals, for example, five days in a row of 75 percent or higher. In a study conducted by Cheney et al. (2008), CCE was implemented with 93 students. After 16 weeks of the intervention it was found that 75 percent of the students reached the 75 percent achievement bench mark and were considered responsive to the intervention. The authors conclude that CCE is an effective technique to support students within mainstream, and that is able to meet students' social, emotional, and behavioural needs. Its success is attributed to providing students with access to positive caring adults, opportunities for success, positive feedback from teachers, greater overall adult acceptance at school, and reinforcement for use of positive social skills. It is noted that training teachers how to give specific positive behavioural feedback is an important component, and that the data collected on the card should be tracked and reviewed every two weeks to allow for adaptations to be made if required.

\section{Social Skills Training}

Social skills programmes aim to deliver intervention to small groups of students and promote social competence, which has been linked to longterm academic achievement and success across many domains of life (Cook \& Tankersley, 2012). Students who lack age-appropriate social skills have disproportionate experiences of poverty and come from cultural minority groups. Their behaviour at school often impacts upon their relationship with their teacher, further slowing the development of pro-social skills and also impacting upon learning (Utley \& Obiakor, 2015). A meta-analysis conducted by Gresham and Elliot (2014) found that, over all, social skills interventions produce a medium effect size, where two out of three children will benefit. It is reported that a factor mediating the success of social skills interventions is whether the intervention is matched to the child's specific social skills needs. It should be determined whether the child has not yet learned the social skills, and the issue is therefore skills acquisition; or whether the child has the skills to perform the desired behaviour however is not engaging in it due to lack of motivation.

A literature review conducted by Elliot and Gresham (2007, cited in Gresham \& Elliot, 2014) identified six components of skill acquisition training interventions which have been empirically supported as effective techniques. These are: Tell (coach), Show (model), Do (rehearsal), Practise (repeat), Monitor progress (selfevaluation), and Generalise (practise behaviour in related environments). An example of a Tier Two skills acquisition intervention is The Cool Tool (Utley \& Obiakor, 2015). This strategy emphasises behavioural expectations and systematically teaches students social skills to reach these. The target students are identified as from vulnerable home situations and have not acquired necessary social skills for school. Pro-social behaviours are explicitly taught across different school contexts (classroom, hallway, etc), rehearsed (role plays), and reinforced through prompts, pre-correction, and praise. In this study, significant outcomes were achieved for increasing on-task behaviour.

Where the child possesses the particular social skill however they are not engaging in it, research suggests that adapting antecedents and consequences in order to illicit positive behaviours is an effective strategy (Cook \& Tankersley, 2012). Replacement Behaviour Training is an intervention designed to promote prosocial behaviour where the child's performance, in particula social skills is the concern (Cook \& Tankersley, 2012). The first step is to complete a functional assessment to determine the child's motive for using the behaviour, then to teach the child to use a replacement behaviour instead, which is already in their repertoire. The replacement behaviour must have the same function as the problematic behaviour in order to meet the child's needs (Cook \& Tankersley, 2012). The environment can then be adapted to decrease the probability of the problem behaviour occurring through reducing antecedents and providing reinforcements for successful use of the replacement behaviour. Positive outcomes of replacement behaviour training addressing social skill performance needs have been reported in various studies including Todd, Horner and Sugai (1999), March and Horner (2002), Christenson, Young and Marchant (2004), and Maag and Larson (2004) (all cited in Cook \& Tankersley, 2012).

By adapting the content, the techniques described above can be applied to a range of common issues including anxiety, peer pressure, and anger management or aggression prevention training (Leff, Waanders, Waasdorp \& Paskewich, 2014). Anxiety management and relaxation training are the 
most commonly-used methods and have the most empirical support (Cook \& Tankersley, 2012). These interventions are able to be delivered to small groups by school mental health professionals over six to eight weeks. Effective programmes have been based on cognitive behavioural therapy (CBT) techniques (Evans, Rybak, Strickland \& Owen, 2014). CBT-based interventions involve explicitly teaching students to recognise the link between their thoughts and behaviour, and their experiences of negative emotions such as anxiety, stress and depression. Students are then taught alternative ways to respond to stressors which reduces negative feelings and improves their resilience (Evans et al., 2012).

An example of this approach within the New Zealand context is the Travellers programme. This programme is targeted at Year 9 students who are experiencing challenging life events such as transitions or loss, and are at higher risk of experiencing emotional distress (Robertson, Boyd, Dingle \& Taupo, 2012). The programme involves a series of small group workshops focusing on teaching strategies for how to cope with challenging life events based on a CBT model. An evaluation of the Travellers programme has been conducted by the New Zealand Council for Educational Research. The evaluation found that overall there was evidence of a moderate improvement in a range of protective factors including access to appropriate support, increased resiliency, and connectedness to the school. There was strong evidence of improved help-seeking skills and more positive relationships with peers/teachers/families (Robertson et al., 2012).

\section{CONCLUSION}

Many schools using a three-tiered model of intervention to meet students' behavioural needs, such as PB4L-SW, are facing challenges when implementing evidence-based Tier Two interventions for at-risk students. The current study has reviewed the literature regarding interventions targeting these students and identified strategies and components emphasised in the literature as important to intervention success. These components have been developed into a checklist to guide schools in their development, implementation and evaluation of Tier Two behaviour supports. The intention is to promote evidence-based practice within schools, whilst also facilitating a flexible approach to be able to meet the needs of individual learners and their families within diverse school settings.

\section{REFERENCES}

Campbell, A., \& Anderson, C. (2008). Enhancing effects of check-in/ check-out with function-based support. Behavior Disorders, 33(4), 233-245.

Cook, B., \& Tankersley, M. (2012). Research-based practices in special education. Boston, United States: Pearson.

Cheney, D., Flower, A., \& Templeton, T. (2008). Applying response to intervention metrics in the social domain for students at risk of developing emotional and behavioral disorders. Journal of Special Education, 42(2), 108-126.

Cheney, D., Stage, S., Hawken, L., Lynass, L., Mielenz, C., \& Waugh, M. (2009). A 2-year outcome study of the check, connect, and expect intervention for students at risk for severe behavior problems. Journal of Emotional and Behavioral Disorders. 17, 226-243.

Debnam, K., Pas, E., \& Bradshaw, C. (2012). Secondary and tertiary support systems in schools implementing school-wide positive behavioral interventions and supports: A preliminary descriptive analysis. Journal of Positive Behavior Interventions, 14(3), 142-152.

Evans, S., Rybak, T., Strickland, H., \& Owen, J. (2014). The role of school mental health models in preventing and addressing children's emotional and behavioral problems. In M. Walker \& F. Gresham (Eds.), Handbook of evidence-based practices for emotional and behavioral disorders: Applications in schools. New York, United States: Guilford Press.

Filter, K. J., McKenna, M. K., Benedict, E. A., Horner, R. H., Todd, A. W., \& Watson, J. (2007). Check in/ check out: A post-hoc evaluation of an efficient, secondary-level targeted intervention for reducing problem behaviors in schools. Education and Treatment of Children, 30(1), 69-84.

Gresham, F., \& Elliot, S. (2014). Social skills assessment \& training in emotional \& behavioral disorders. In M. Walker \& F. Gresham (Eds.), Handbook of evidence-based practices for emotional and behavioral disorders: Applications in schools. New York, United States: Guilford Press.

Hawken, L. S., Bundock, K., Kladis, K., O'Keeffe, B., \& Barrett, C. A. (2014). Systematic review of the check-in, check-out intervention for students at-risk for emotional behavioral disorders. Education and Treatment of Children, 37, 635-658.

Hawken, L. \& Horner, R. (2003). Evaluation of a targeted group intervention within a school-wide system of behavior support, Journal of Behavioral Education, 12, 225-240. 
Hawken, L. S., MacLeod, K. S., \& Rawlings, L. (2007). Effects of the behavior education program (BEP) on problem behavior with elementary school students. Journal of Positive Behavior Interventions, 9, 94-101.

Hill, D., \& Brown, D. (2013). Supporting inclusion of at risk students in secondary school through positive behaviour support. International Journal of Inclusive Education, 17(8), 868-881.

Hoyle, G., Marshall, K., \& Yell, M. (2011). Positive behaviour support: Tier two interventions in middle school. Preventing School Failure, 55(3), 164-170.

Lane, K., Capizzi, A., Fisher, M., \& Ennis, R. (2012). Secondary prevention efforts at the middle school level: An application of the behavior education program. Education and Treatment of Children 35(1), 51-90.

Lane, K., Kalberg, J., \& Menzies, H. (2009). Developing schoolwide programs to prevent and manage problem behaviors: A step-by-step approach. New York, United States: Guilford Press.

Leff, S., Waanders, C., Waasdorp, T., \& Paskewich, B. (2014). Bullying and aggression in school settings. In M. Walker \& F. Gresham (Eds.), Handbook of evidence-based practices for emotional and behavioral disorders: Applications in schools. New York, United States: Guilford Press.

Lewis, T., \& Sugai, G. (1999). Effective behavior support: A systems approach to proactive schoolwide management. Focus on Exceptional Children, 31(6), 24-99.

March, R. E., \& Horner, R.H. (2002). Feasibility and contributions of functional behavioral assessment in schools. Journal of Emotional and Behavioral Disorders, 10, 158-170.

McCurdy, B. L., Kunsch, C., \& Reibstein, S. (2007). Secondary prevention in the urban school: Implementing the behavior education program. Preventing School Failure, 12-19.

McIntosh, K., Campbell, A., Carter, D., \& Dickey, C. (2009). Differential effects of a tier two behavioral intervention based on function of problem behavior. Journal of Positive Behavior Interventions, 11(2), 82-93.

Ministry of Education (2015). Positive behaviour for learning overview 2015. Ministry of Education: Wellington, New Zealand.

Ministry of Education (2016). Positive behaviour for learning. Retrieved April 2016 from: http://pb4l.tki.org.nz/PB4L-School-Wide

Robertson, S., Boyd, S., Dingle, R., \& Taupo, K. (2012). Evaluation of skylight's travellers programme: Final report. Ministry of Health: Wellington, New Zealand.
Sugai, G., \& Horner, R .H. (2002). The evolution of discipline practices: School-wide positive behavior supports. Child and Family Behavior Therapy, 24, 23-50.

Sugai, G., \& Horner, R. (2006). A promising approach for expanding and sustaining the implementation of school-wide positive behavior support. School Psychology Review, 35, 245-259.

Sugai, G., Horner, R., \& Gresham, F. (2002). Behaviorally effective school environments. In M. R. Shinn, G. Stoner \& H. M Walker (Eds.), Interventions for academic and behavior problems: Preventive and remedial approaches. National Association of School Psychologists. Silver Spring, MD.

Todd, A., Campbell, A., Meyer, G., \& Horner, R. (2008). The effects of a targeted intervention to reduce problem behaviors: Elementary school implementation of check in - check out. Journal of Positive Behavior Interventions, 10(1), 46-55.

Utley, C., \& Obiakor, F. (2015). Measuring the cool tool as a targeted intervention to minimize teacher reprimands and students' on-task behaviour in urban elementary school. Learning Disabilities: A Contemporary Journal, 13(1), 43-57.

\section{AUTHOR PROFILE}

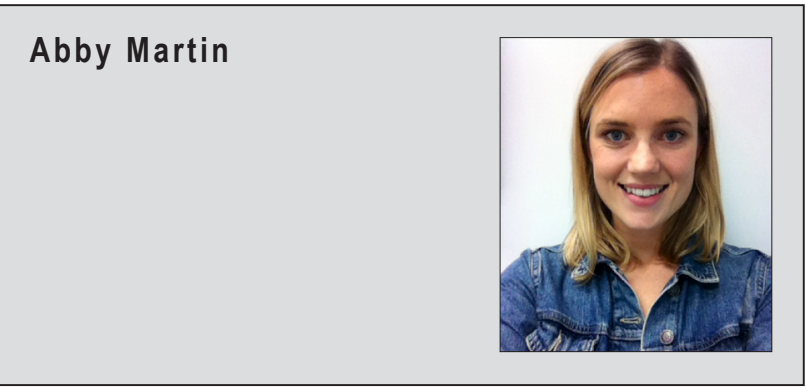

Abby Martin has a Masters in Educational Psychology from Massey University. Her previous research topics have included the impact of an alternative education programme on outcomes for homeless youth, including life satisfaction, housing stability, and employment status. She is currently completing her educational psychology internship through Massey University and has a placement on the severe and challenging behaviour team in Auckland central.

Email: avf.martin@gmail.com 